\title{
Admissions Constraints and the Decision to Delay University
}

\author{
Foley, Kelly; Groes, Fane Naja
}

Document Version

Accepted author manuscript

Published in:

The Scandinavian Journal of Economics

DOI:

$10.1111 /$ sjoe. 12405

Publication date:

2021

Citation for published version (APA):

Foley, K., \& Groes, F. N. (2021). Admissions Constraints and the Decision to Delay University. The

Scandinavian Journal of Economics, 123(2), 478-507. https://doi.org/10.1111/sjoe.12405

Link to publication in CBS Research Portal

\section{General rights}

Copyright and moral rights for the publications made accessible in the public portal are retained by the authors and/or other copyright owners and it is a condition of accessing publications that users recognise and abide by the legal requirements associated with these rights.

Take down policy

If you believe that this document breaches copyright please contact us (research.lib@cbs.dk) providing details, and we will remove access to the work immediately and investigate your claim. 


\title{
Admissions Constraints and the Decision to Delay University Kelly Foley, Fane Naja Groes
}

\author{
Journal article (Accepted manuscript*)
}

\section{Please cite this article as:}

Foley, K., \& Groes, F. N. (2019). Admissions Constraints and the Decision to Delay University. The Scandinavian Journal of Economics. https://doi.org/10.1111/sjoe.12405

This is the peer reviewed version of the article, which has been published in final form at 00 : https://doi.org/10.1111/sjoe.12405

This article may be used for non-commercial purposes in accordance with Wiley Terms and Conditions for Self-Archiving

* This version of the article has been accepted for publication and undergone full peer review but has not been through the copyediting, typesetting, pagination and proofreading process, which may lead to differences between this version and the publisher's final version AKA Version of Record. 


\title{
Admissions Constraints and the Decision to Delay University
}

\author{
Kelly Foley* \\ University of Saskatchewan, \\ Saskatoon, Canada, S7N5A5. \\ Email: kelly.foley@usask.ca.
}

Fane Groes

Copenhagen Business School, Frederiksberg, Denmark, 2000.

Email: fg.eco@cbs.dk.

\begin{abstract}
We investigate whether delaying entrance into university is affected by restrictions on admissions into competitive programs. Using Danish administrative data, we estimate a dynamic discrete choice model, in which students choose, if admitted, whether to enter one of 30 programs or delay. We use the model to examine delaying choices under different simulated admissions policies. Our experiments suggest that only $28 \%$ of students who delay do so because of admissions restrictions. Furthermore, although students respond to admissions incentives, our results imply that such policies are unlikely to substantially change the overall distribution of delay.
\end{abstract}

Keywords:University admissions policies; Timing of university enrollment JEL Classification:I2;J24

*This research was supported by a grant from the Danish Research Council. The authors are grateful for helpful comments from Nicole Fortin, David Green, Oskar Nordström Skans, Andreas Pollak, Ben Sand, members of The Centre for Applied Microeconometrics, The Copenhagen Education Network and The Canadian Labour Economics Forum.

This article has been accepted for publication and undergone full peer review but has not been through the copyediting, typesetting, pagination and proofreading process, which may lead to differences between this version and the Version of Record. Please cite this article as doi:

$10.1111 /$ sjoe. 12405

This article is protected by copyright. All rights reserved. 


\section{Introduction}

Compared to the amount of attention that has been directed toward understanding the decision to attend university, the issue of when to attend receives relatively little attention. Yet, taking a year or two off between high school and university is observed in many countries. Although statistics are not widely available in the United States, one study estimates that, among new entrants, roughly one third have delayed by at least one year (Horn and Malizio, 2002). The practice of delaying entrance into higher education is more common in Europe. Recent statistics suggest that more than $40 \%$ of German tertiary education students delay by at least one year (Eurostudent, 2015). Delaying is most common in Nordic countries. For example, a survey conducted in 2016 suggests that only $43 \%$ of Norwegian students enter higher education directly from high school. In this paper, we focus on high school graduates in Denmark, where delaying is also wide spread. Indeed, in administrative data, among those who entered a bachelors degree in 2009, only 1 in 5 went directly from high school.

The literature that does investigate the timing of post-secondary schooling tends to focus on how delays and interruptions affect earnings and wages, while far less is known about why students delay. Understanding the underlying motives is useful to help interpret evidence on the economic costs and benefits of delaying, and to also understand what, if any, policy responses are warranted. As Holmlund et al. (2008) point out there are at least five different ways of categorizing the reasons students may delay, which are investing in skills, engaging in leisure activities, learning about preferences and ability, military service and waiting for better educational opportunities. ${ }^{1}$

\footnotetext{
${ }^{1}$ In institutional contexts where tuition is high and loans and grants are not widely available to cover living expenses, saving money for schooling is another potentially important reason for delaying.
} 
In this paper, we examine the importance of the latter reason-waiting for better educational opportunities-in explaining delaying. Although the mechanisms by which scarce positions in university programs are allocated vary across time and countries, it is rarely the case that no admissions restrictions exist. Competition for admissions into programs with high demand relative to supply might generate incentives to delay in a variety of admissions systems. We exploit features of the Danish university admissions system from the early 1980's to help quantify the extent to which students delay because they are constrained from entering a preferred program. In the policy environment we study the number of places in any given program were fixed on an annual basis. When student demand for programs exceeded the supply, admissions were allocated on the basis of students' high school grade point average (GPA). Because demand and supply varied from year to year, the GPA required to enter a given program also fluctuated. For this reason, and because of other features of the policy that rewarded full-time employment in admissions, there were incentives for students who may not be admitted to a preferred program in a given year to delay their entrance into university.

In addition to the apparent incentives to delay imbedded in the policy, we also note that, in administration data, the propensity to delay entrance into university varies substantially with the field of study entered. This empirical pattern further points toward a link between admissions policies and the timing of entrance. To investigate this link, we develop and estimate a dynamic discrete choice model that is governed by the Danish admissions system in effect during our sample period. In our three-period model, students choose between entering one of 30 university programs at 8 different universities or delaying to the next period. To estimate the model, we use data from the Danish population registers covering students who 
graduated from high school in the years 1981-1984 and entered university within 2 years. In addition to parametric assumptions, the model is identified using exogenous variation in the minimum GPA required to enter a program. A structural approach is critical in this context because delaying and choosing a field of study are simultaneously determined. Indeed, the decision to delay can be framed as the decision not to enter any field of study in any given year.

We use the model to gauge the extent to which the timing of students' entry into university is affected by admissions constraints. We simulate experiments that compare decisions made in a policy environment with open admissions to different counterfactuals with admissions constraints that fluctuate in future periods. An open admissions system would clearly represent an upper bound on relaxing admissions restrictions, and is not proposed a feasible policy option. Instead, with this thought experiment, we use revealed preference arguments to identify choices that are constrained by admissions restrictions.

Compared to the admissions system from the sample period, holding all else constant, we find that the fraction of students with zero years of delay increases by roughly 9 percentage points in the hypothetical open-admissions system. Our structural approach allows us to quantify the gross flows that generate this net effect.

Our simulated counterfactuals suggest that among students who delay entrance into university $27.5 \%$ do so because of admissions restrictions. This group represents $12.5 \%$ of all students in the sample. These students delay by either one or two years, and in the absence of any admissions constraints, we find that most of these delayers would enter directly from high school.

While our model predicts that only $12.5 \%$ of the sample delay because of admission 
restrictions, we find that a further $13.3 \%$ of the sample would enter a different program in the absence of restrictions. This group would not, however, delay for that possibility when the restrictions are present. As a consequence, relaxing admissions restrictions shifts the distribution of field of study, in some cases, without also reducing delaying. In particular students flow into Medicine, which consistently has high excess demand. However, when admissions are open in all programs except Medicine, our counterfactuals suggest that delay falls by roughly the same amount but the shifts in the distribution of field of study are fairly small.

Taken as a whole, our results suggest that some students do alter the timing of their entrance into university in response to admissions restrictions. However, as a fraction of all students delaying, this group represents a minority. As such, it is unlikely that policies, such as GPA multipliers that confer advantages in admissions for students who enroll directly after high school, will substantially alter the overall distribution of delay. ${ }^{2}$

The rest of the paper proceeds by first reviewing the relevant literature and then by describing, in brief, the Danish schooling system, and the admissions system during our sample period. In the next two sections, we introduce our data and describe the individual characteristics associated with delaying university. In this section, we also document the relationship between delaying and field of study. Next, we introduce the discrete choice model, and explain how it is identified and estimated. In the results section, we begin by discussing how well the model fits the data and can predict changes outside of the sample.

\footnotetext{
${ }^{2}$ Beginning in 2009, in Denmark, students who entered university directly from high school had their GPA inflated by 1.08. That policy will be discontinued in 2020, ostensibly to increase students' flexibility. (Ingvorsen, Emil, "Ny bred aftale: Karakterbonus på 1,08 bliver sløjfet", (New Broad Deal: Character Bonus of 1.08 will be dropped.) December 6, 2018 https://www.dr.dk/nyheder/politik/ ny-bred-aftale-karakterbonus-paa-108-bliver-sloejfet)
} 
We then discuss the main findings from the simulated counterfactual experiments. Finally, we offer some concluding comments.

\section{Previous Research}

Depending on the data and the nature of the delay, the findings are mixed in the literature investigating how delaying and interrupting schooling affects labour market outcomes. In a sample of Canadian post-secondary graduates, Ferrer and Menendez (2014) find that postschooling wages are higher for those who delayed their entry, particularly for those who worked during the delay. In contrast, two U.S. studies suggest that delaying is associated with lower returns to completed schooling, although those losses are not uniform across different levels of schooling. Light (1995) reports that, on average, among white men with the same amount of schooling, those who completed without interruption earned a higher premium. In a broader sample including women and minorities, Monks (1997) finds that the returns to education are lower for people who graduate from college after age 25 .

Studies with access to panels of earnings have found initial earnings losses that eventually fade away. Using data from a British panel of the cohort born in 1970, Crawford and Cribb (2012) report that delaying higher education by up to three years reduces average earnings at age 30 . By age 38 , this difference is small and no longer statistically significant. Using Swedish data that is most similar to ours, Holmlund et al. (2008) find that, delaying university by two or more years is associated with lower earnings at age 30. Overtime the earnings gap closes so that delaying has no impact on earnings by age 42. Overall, however, Holmlund et al. (2008) estimate a total loss in the discounted present value of lifetime earnings amounting to 40 to $50 \%$ of one year of age- 40 earnings. 
While earnings and wages are a useful summary statistic for the many ways in which delaying might impact productivity, these outcomes do not provide much direct evidence about why students delay. As Holmlund et al. (2008) suggest, there are a variety of reasons why students may delay including because they were not admitted into their preferred program, which is the issue we pursue in this paper.

A recent but rapidly growing literature suggests that the decision of which field of study to enter is as, if not more, important as the decision to pursue higher education. Indeed, wage differences across fields of study have been found to be as large as the average return to university (Altonji et al., 2012; Lemieux, 2014; Altonji et al., 2016). Moreover, evidence of comparative advantage across fields of study implies that a student who might have above average earnings in one field could earn below the average in a different field (Kirkeboen et al., 2016). Even if waiting to be admitted to a particular program does not lead to higher earnings net of any costs, other studies have pointed toward substantial non-monetary returns that vary across occupations, which are linked to different fields of study (Arcidiacono, 2004; Arcidiacono et al., 2014). Taken as a whole, this literature suggests that there may be incentives for individuals to delay if it means they can enter a preferred field of study.

We build on these literatures by directly investigating the extent to which delaying is driven by admissions constraints. Relatedly, other researchers have taken advantage of a feature in admissions systems from different countries, which generates discontinuities around a threshold grade point average, to investigate the impact of being admitted into specific programs on future earnings (Hastings et al., 2013; Kirkeboen et al., 2016; Heinesen, 2018; Daly and le Maire, 2019), and the impact of not being admitted into a program on fertility (Humlum et al., 2017). Such identification strategies employing GPA discontinuities generally 
require restricting attention to those who have applied for university. Applicants are only a subset of all delayers, and admissions constraints might influence the decision to delay even among non-applicants. Consequently, while we make use of similar variation, because our work focuses on the decision to delay, our approach combines exogenous variation in admissions with structure. The structural approach further allows us to add to this literature by assessing to what extent delaying responds to different admissions incentives.

\section{Danish School System}

During our sample period, Denmark had 9 years of compulsory schooling. Following that, students who wished to qualify for university would enroll in an academic high school, which are called gymnasium in Danish. There were three types of high schools: ordinary, business, or technical. We focus on ordinary high school, which was the most common type. Students in these high schools could choose between two concentrations-a 'language track', with more courses in European and classical languages, or a 'math track', with more math and science courses. To enter university programs, high school graduates needed to have achieved a minimum score of 6 on a 13-point grade scheme in their qualifying exams. Some programs, particularly sciences, also required completion of specific courses, however, these prerequisites could be met by taking additional courses in university.

Students who were eligible for university would apply through a centralized application system referred to as KOT. ${ }^{3}$ During the sample period, capacity at each university for specific programs was established by the Ministry of Education in consultation with administrators

\footnotetext{
${ }^{3}$ Information regarding the admissions system in place during this period was taken from Studie og Erhvervsvalget, Speciel del (Study and Occupational Choice, Special Report), published by Rådet for Uddannelses- og Erhvervsvejledning in the years 1982, 1983, 1984, 1985-86, 1986-87.
} 
from the various institutions. The national government also legislated that a certain fraction of positions were allocated to students applying through three different pathways. Most of the capacity, 60-70 percent, was allocated to 'Group I', in which students were admitted solely on the basis of their GPA. Another $20 \%$ were allocated to applicants with work experience. The GPA of applicants applying through this channel, which was called 'Group II', was inflated by a factor that increased with the amount of work experience. ${ }^{4}$ Specifically, the GPA of applicants with 9-11 months of experience was inflated by 1.09 , and by 1.18 for those with at least 18 months of experience. This system was introduced in 1977 around the same time that restrictions were placed on the number of students who were admitted to specific programs. Positions were to be allocated by high school GPA, but law makers wanted to allow for a channel that would also take work experience into account, because they thought that work could help students make an informed and successful match with the best field of study. ${ }^{5}$

When applying, students in Group I submitted to KOT a prioritized list of programs. KOT then ranked the students according to their GPA. The Group I program capacity was allocated starting with the students with the highest GPAs. Thus, the students with the highest GPA were offered their first priority program and the likelihood of being offered a place in one's first choice program declined with GPA. If all of the positions in preferred programs had been offered to other students with higher GPAs, a student would be offered the next program on their priority list. This admissions process generated a GPA threshold

\footnotetext{
${ }^{4}$ This admissions class differs somewhat from the current system, first introduced in 1991, called 'Quota 2'. Under Quota 2, students are evaluated by more than just their GPA, and this can include work experience or admissions essays. In the current system, students can apply in Quota 2 and Quota 1 simultaneously.

5 "Bekendtgørelse af lov om adgangsregulering ved videregående uddannelser" Forslag til Lov om Adgangsregulering ved videregaaende uddannelse, 1976, tillaeg A, B, and C (A: spalte 4025, B: spalte 1797, C: spalte 769). BK nr 742 af 31/10/1986. (Publication of the Access Control Act in Higher Education Proposed Law on Access Control in Higher Education) A third class of admissions, allocated roughly 10 to $20 \%$ of the positions, was reserved for students over age 25 without a high school diploma, and students who studied outside of Denmark. This third group is not a part of our sample.
} 
in all of the programs for which there was excess demand. A similar process was followed for Group II, except that an applicant's GPA would have been adjusted according to the student's work history. Since the thresholds for both Group I and Group II were a function of relative supply and demand for each program, the exact cut-off value in future years could not be predicted by applicants. We use this source of variation in identifying the model, which we will discuss later in greater detail.

Danish universities did not charge any tuition or fees, and generous grants were available for students from lower income families. Until 1988, grant eligibility depended on parents' income for students below the age of 22. A reform implemented in that year lowered the age at which parental means-testing was required to $19 .^{6}$

\section{Data}

We use data drawn from administrative registers, which cover $100 \%$ of the Danish population. In our estimating sample, we include individuals who were born in Denmark and who graduated from an 'ordinary' high school between the ages of 17 and 20. Our estimating sample includes the high-school graduating cohorts of 1981-1984. Our sample period ends in 1984 because the GPA thresholds we use for identification were not published for 1987 in our source of that data. We also have data for the 1980 cohort, which we reserve to assess how well our model fits the data. We further restrict the sample to students who entered one of 30 different programs at 8 major Danish universities within 2 years of their terminal high school program. ${ }^{7}$ Table 1 lists each of the sample programs categorized by university and

\footnotetext{
${ }^{6}$ Nielsen et al. (2010) study the effect of that expansion in aid and conclude that borrowing constraints were unimportant in Denmark.

${ }^{7}$ There are two reasons why we censor at two years of delay. First, the Group II GPA inflator reaches a maximum at 18-months of work experience. The second reason is related to the missing GPA thresholds
} 
field of study. ${ }^{8}$ There are five broad fields of study, which are Humanities, Natural Sciences,

Social Sciences, Engineering, and Medicine. We define the student's field of study according

to the program they entered first. ${ }^{9}$

Table 1: Sample Programs, by Field of Study and Universities

\begin{tabular}{|c|c|c|c|c|c|}
\hline \multirow[b]{2}{*}{ Universities } & \multicolumn{5}{|c|}{ Faculties } \\
\hline & Humanites & Natural Sciences & Social Sciences & Engineering & Medicine \\
\hline University of Copenhagen (KU) & $\begin{array}{l}\text { Theology } \\
\text { Humanities }\end{array}$ & $\begin{array}{c}\text { Biology } \\
\text { Other natural sciences }\end{array}$ & $\begin{array}{c}\text { Law } \\
\text { Business/Economics } \\
\text { Political Science }\end{array}$ & & Medicine \\
\hline Aarhus University (AU) & $\begin{array}{l}\text { Theology } \\
\text { Humanities }\end{array}$ & $\begin{array}{c}\text { Biology } \\
\text { Other natural sciences }\end{array}$ & $\begin{array}{c}\text { Law } \\
\text { Business/Economics } \\
\text { Political Science }\end{array}$ & & Medicine \\
\hline University of Southern Denmark (SDU) & Humanities & Natural Sciences & Business/Economics & & Medicine \\
\hline $\begin{array}{l}\text { Roskilde University (RU) } \\
\text { Aalborg University (AAU) }\end{array}$ & $\begin{array}{l}\text { Humanities } \\
\text { Humanities }\end{array}$ & Natural Sciences & $\begin{array}{l}\text { Social Sciences } \\
\text { Social Sciences }\end{array}$ & Engineering & \\
\hline Danish Technical University (DTU) & & & & Engineering & \\
\hline Aarhus Business School (ABS) & & & Business/Economics & & \\
\hline Copenhagen Business School (CBS) & & & Business/Economics & & \\
\hline
\end{tabular}

Notes: Programs are categorized into field of study according to the Statistics Denmark classification.

For our sample, we combine data from four different administrative registers with university admissions and funding data so that we observe a number of important schooling and labour market outcomes. First, from the Danish Student Register, we observe, annually, enrollment and any credentials obtained from specific university programs and institutions. For individuals who graduated from ordinary high schools, we observe the average high school grade which was used to qualify for university. In the second register, the Integrated Database for Labour Market Research (IDA), we observe annual earnings and other labour market in the 1987 archived report. If we add an additional year of delay in the model, we will lose a cohort of data, which we prefer not to do since much of the identifying variation is cross-cohort variation. In Online Appendix $\mathrm{J}$, we report estimates from a four period model, which does not change any of our key findings.

${ }^{8}$ The sample programs represent $80 \%$ of all the fixed enrollment quotas at the 8 universities during the sample period.

${ }^{9}$ Students who might want to switch programs would be required to apply again through the normal admissions process. In our data, $76 \%$ of the students are still enrolled in the same field of study in their fourth year of study. Among those who are still enrolled in any candidature $91 \%$ are enrolled in the same field. 
outcomes. This register is used to construct our expected lifetime earnings measures, as well as earnings during years of delay. Third, we use a demographic register, which links the individuals to their parents, to construct age, sex, geographic, and family background variables. Finally, from an income register, we obtain annual records of the amount of student financial aid received. We summarize the sample data for selected variables in Table 2.

Table 2: Sample Means (Standard Errors For Continuous Variables in Parentheses)

\begin{tabular}{|c|c|c|c|c|}
\hline & \multirow[t]{2}{*}{ Total } & \multicolumn{3}{|c|}{ Years of Delay } \\
\hline & & Zero & One & Two \\
\hline \multicolumn{5}{|l|}{ Years of Delay } \\
\hline Zero years & 0.546 & & & \\
\hline One year & 0.295 & & & \\
\hline Two years & 0.158 & & & \\
\hline High school exam grades & $\begin{array}{c}8.65 \\
(0.007)\end{array}$ & $\begin{array}{c}8.766 \\
(0.009)\end{array}$ & $\begin{array}{c}8.57 \\
(0.013)\end{array}$ & $\begin{array}{c}8.4 \\
(0.017)\end{array}$ \\
\hline Female & 0.362 & 0.305 & 0.413 & 0.465 \\
\hline Age at high school graduation & $\begin{array}{l}19.162 \\
(0.005)\end{array}$ & $\begin{array}{c}19.144 \\
(0.007)\end{array}$ & $\begin{array}{l}19.185 \\
(0.009)\end{array}$ & $\begin{array}{c}19.18 \\
(0.012)\end{array}$ \\
\hline Mathematics Track & 0.759 & 0.813 & 0.718 & 0.652 \\
\hline \multicolumn{5}{|c|}{ Earnings and Student Aid, all in millions of real (Year 2000) DKK } \\
\hline Discounted Lifetime Earnings After Starting University & $\begin{array}{c}5.56 \\
(0.025)\end{array}$ & $\begin{array}{c}5.821 \\
(0.035)\end{array}$ & $\begin{array}{c}5.109 \\
(0.062)\end{array}$ & $\begin{array}{c}5.109 \\
(0.062)\end{array}$ \\
\hline Discounted Student Financial Aid & $\begin{array}{c}0.135 \\
(0.001)\end{array}$ & $\begin{array}{c}0.121 \\
(0.001)\end{array}$ & $\begin{array}{c}0.157 \\
(0.001)\end{array}$ & $\begin{array}{c}0.157 \\
(0.001)\end{array}$ \\
\hline Earnings in first year of delay & & & $\begin{array}{c}0.05 \\
(0.0005)\end{array}$ & $\begin{array}{c}0.048 \\
(0.001)\end{array}$ \\
\hline Earnings in second year of delay & & & & $\begin{array}{c}0.100 \\
(0.001)\end{array}$ \\
\hline Sample Size & 16,996 & 9,284 & 5,019 & 2,693 \\
\hline
\end{tabular}

Notes: A discount rate of 4 percent is used. Lifetime earnings is calculated using the actual income in the first 23 years after a student enters university. Earnings beyond the first 23 years are projected out to age 60 using the individuals' average earnings across years 21 to 23 .

We collected the admissions data from archival reports produced by KOT. The reports were published annually in July and contain information on the total number of places available in each program across Denmark, the number of applicants, the GPA threshold for each admissions class and the number of positions still available. We also use data collected from annual publications of the "Finance Act", which specifies funding levels for universities 
broken down by the field of study. Specifically, we use the projected student-to-teacher ratios upon which grant allocations were based.

\section{Who delays?}

Before presenting the structural model, we begin by examining which, if any, individual characteristics are associated with delaying university. In Table 3, we report estimates from an OLS regression where the dependent variable is an indicator for whether the individual delayed by one or two years. Family background appears to be only weakly related to delaying. The positive correlation between family income and delaying is only marginally statistically significant. Although father's education does not predict delaying, compared to students whose mother completed a university degree, those whose mother completed a medium cycle education are 5.6 percentage points more likely to delay.

In contrast, a student's sex, high school track, and GPA are strong predictors of delay. In the data, woomen are roughly 11 percentage points more likely to delay than men. This is despite the fact that some fraction of the men delaying university may have been participating in compulsory military service. ${ }^{10}$ Students who pursue the mathematics track (as opposed to the language track) are almost 14 percentage points less likely to delay university. Individuals with higher high school grades are also less likely to delay. On average, a one standard deviation difference in high school GPA, which is 0.92 , is related to a 8.8 percentage point difference in the likelihood of delaying. ${ }^{11}$

\footnotetext{
${ }^{10}$ During the sample period, military service was compulsory for a fraction of 18 year-old men selected by lottery. In 1979, $27 \%$ of all 18 year-old men were conscripted while in 1989, $24 \%$ were conscripted (Sorensen, 2000). We are unfortunately unable to explore this further because military service is not well observed in the Danish registers that we are using.

${ }^{11}$ This set of characteristics is also used to predict expected lifetime income outside the model. In the structural model, the decision to delay or enter a program is conditional on a different set of variables that vary across programs, and include the predictions for expected lifetime income.
} 
Table 3: Characteristics Associated With Delaying University(Standard Errors in Parentheses)

\begin{tabular}{lc}
\hline & $0.114^{* * *}$ \\
Female & $(0.011)$ \\
& $-0.096^{* * *}$ \\
High School GPA & $(0.004)$ \\
& $0.020^{*}$ \\
Ln family income & $(0.008)$ \\
& Age at high school graduate - Reference
\end{tabular}

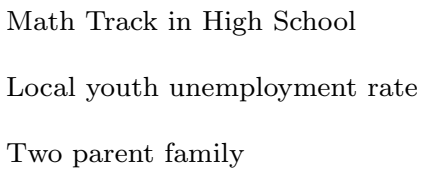

Math Track in High School

Local youth unemployment rate

Two parent family

Age 19

-0.006
$(0.030)$

0.003

(0.033)

Parents' Education -Long Cycle Education

\section{Mother}

$\begin{array}{lc}\text { High school or Less } & -0.015 \\ & (0.019) \\ \text { Vocational } & -0.013 \\ & (0.019) \\ \text { Short Cycle } & 0.029 \\ & (0.023) \\ \text { Medium Cycle } & 0.056^{* *} \\ & (0.018) \\ \text { Data missing } & 0.040 \\ & (0.026)\end{array}$

$-0.139^{* * *}$

(0.009)

$-0.057$

$(0.138)$

$-0.012$

$(0.011)$

0.014

$(0.031)$

Sample Size

16,996

R-squared

0.009
$(0.013)$
-0.009
$(0.012)$
0.026
$(0.023)$
-0.002
$(0.013)$
-0.010
$(0.016)$

Notes: Coefficients and standard errors are estimated in a linear probability model where the dependent variable takes on the value 1 if an individual delayed by one or two years, and zero if the individual entered university directly from high school. The regression also includes indicators for the municipality of residence in the last year of high school, and high school graduating cohort.

The relationship we observe between delaying and grades is consistent with the view that some students might delay because they hope to be admitted to a preferred university program. Furthermore, the likelihood of having delayed entrance into university varies substantially depending on the field of study entered. Across the whole sample, $45 \%$ enter university after a delay of one or two years. Students who enter the Natural Sciences, delay at rates close to the average $(44 \%)$ respectively. In fields of study with the most competitive programs-Medicine and Social Science- the rate of delaying is just above average, $48 \%$ and 49\%, respectively. Humanities students are by far the most likely to delay entrance. Indeed, only $39 \%$ of Humanities students entered without delay. This behaviour is in stark contrast 
to Engineering graduates, among whom $70 \%$ enter university directly. Because of the stark contrast in the propensities to delay across fields of study, we model the decision to delay jointly with the decision to enter a particular field. The structure of the model allows us to uncover the extent to which the decision to delay is a result of admissions restrictions.

\section{Model}

In this section, we describe the dynamic three-period model that we use to investigate how the timing of university enrollment might change under different admissions policies. In the model, individuals choose between delaying or entering one of 30 different university programs. Entering a program is an absorbing state and students delay at most two years. A student can only enter a program for which they are qualified, meaning that their own high school GPA is above a program- and year-specific threshold GPA in the relevant admissions class. Students entering programs directly from high school apply through the Group I admissions class. After delaying, students apply through Group II, and have their GPA inflated by a factor that depends on their years of delay. ${ }^{12}$ For most students, delaying changes the set of programs for which they are eligible. ${ }^{13}$

\section{Instantaneous Utility}

We assume the instantaneous utility that student $i$ experiences from entering program $p$ in period $g$ is a linear function of the present value of the income stream, non-pecuniary benefits,

\footnotetext{
${ }^{12}$ We do not observe hours worked, and so we assume that students who delay for one year are eligible for the 1.09 GPA multiplier, and students who delay by two are eligible for the 1.18 multiplier.

${ }^{13}$ After two years of delay, the Group II threshold is always lower than the Group I threshold. However, after only one year of delay, because the GPA multiplier is smaller, in some high excess demand programs the Group II threshold is higher than that in the Group I admissions class.
} 
and an unobserved preference shock $\epsilon_{i p g}^{S}$ :

$$
\begin{aligned}
U_{i p g}^{S} & =v_{i p g}^{S}+\epsilon_{i p g}^{S} \\
& =\alpha_{f}+\alpha_{x} X_{i p f}+P V \text { earn }_{i p g}+P V S F A_{i g}+\epsilon_{i p g}^{S}
\end{aligned}
$$

Income includes earnings ( $P V$ earn $\left.n_{i p g}\right)$, which vary by program and years of delay, and student financial aid $\left(P V S F A_{i g}\right)$, which depends only on years of delay. The program characteristics $\left(X_{i p f}\right)$, which are indexed by $f$ if common across the field of study, include indicators for whether one's mother and father hold a candidature in the program's field of study and indicators for whether the program is in the same city or region in which the students lived during their last year of high school. This vector also includes the ratio of students to academic staff, which varies by university, as well as field of study and cohort. ${ }^{14}$

We also allow utility during school to depend on whether the field of study a student enters matches their sex and high school track, where 'matching' means the majority of the students have the same sex or high school track. ${ }^{15}$ The indicator for whether a student's high school track matches their field of study can capture any additional effort that is required when, for example, a language-track student enters Natural Sciences. Finally, utility from entering a program includes a field-of-study specific intercept, $\alpha_{f}$.

Rather than entering a program, students can delay for a year. The utility from delaying

\footnotetext{
${ }^{14}$ We include more details about the construction of these variables in Online Appendix A

${ }^{15}$ Two faculties, Humanities and Medicine, are dominated by women, while the other three are dominated by men. This specification allows the utility of entering a male or female dominated field to differ across men and women. With respect to high school concentration, Natural Science, Engineering, and Medicine are coded as math-track fields of study, and the others are language-track.
} 
university by one year, conditional on having delayed by $g$ years is:

$$
\begin{aligned}
U_{i g}^{G} & =v_{i g}^{G}+\epsilon_{i g}^{G} \\
& =\gamma_{s g}+\gamma_{h g}+\gamma_{c}+\gamma_{u} \text { unemp }_{i g}+\gamma_{a} \text { age } e_{i g}+\text { earn }_{i g}+\epsilon_{i g}^{G}
\end{aligned}
$$

To capture differences in the nature of work or other activities pursued during a gap year, the value of delaying depends on the students' sex $\left(\gamma_{s g}\right)$ and high school track $\left(\gamma_{h g}\right)$. For example, men might be doing military service. Delaying also depends on the high school graduating cohort $\left(\gamma_{c}\right)$, students' current age, their earnings during the year of delay, the local youth unemployment rate, and a random component $\left(\epsilon_{i g}^{G}\right)$.

\section{Optimization problem}

In any given period, students choose between entering one of the programs for which they are eligible, or, in the first two periods, delaying. We formalize these decisions as a dynamic discrete choice problem, in which there are three sets of state variables. The first is a vector of preference shocks, $\epsilon_{i g}=\left\{\epsilon_{i g}^{G}, \epsilon_{i 1 g}^{S}, \ldots, \epsilon_{i 30 g}^{S}\right\}$, where $\epsilon_{i 2}^{G}=0$.

The second state variable, called $G_{i g}$ is the number of previous years of delay. Finally, the third state variable comes from the fact that students can only enter programs for which they are qualified. If $q_{i p g}$ is an indicator that equals one if an individual is qualified for program $p$ in period $g$, and zero otherwise, then we can define the state variable $Q_{i g}$ as the vector of indicators for all programs in period $g$.

The control variable is a vector of indicators that sum to one and summarize the decision to delay or enter one of the programs. If the index $p=0$ denotes the decision to delay, and each of the programs are indicated by the values between one and 30, then the control variable is $d_{i g}=\left\{d_{i g}^{0}, d_{i g}^{1}, \ldots, d_{i g}^{30}\right\}$. 
In the final period, since all students enter a program $d_{i 2}^{0}=0$. Using these definitions, the optimization problem can be summarized by the Bellman equation:

$$
\begin{aligned}
V_{i g}\left(\epsilon_{i g}, Q_{i g}, G_{i g}\right)=\max _{d_{i g}} & \mathbb{E}_{g}\left[\sum_{p=1}^{30} d_{i g}^{p} q_{i p g} U_{i g p}^{S}+d_{i g}^{0}\left(U_{i g}^{G}+\beta V_{i g+1}\left(\epsilon_{i g+1}, Q_{i g+1}, G_{i g+1}\right)\right)\right] \\
& \text { for } g \in\left\{0,1,2 \mid g=G_{i g}\right\} \\
\text { s.t. } \quad & \left(1-q_{i p g}\right) d_{i g}^{p}=0 \forall p=\{1 \cdots 30\} \\
& Q_{i g+1}=f\left(G_{i g}\right) \\
& G_{i g+1}=G_{i g}+d_{i g}^{0}, \quad G_{i 0}=0 \\
& \sum_{p=0}^{30} d_{i g}^{p}=1
\end{aligned}
$$

The maximization problem is expressed as conditional on $g=G_{i g}$ because entering a program is an absorbing state. The first constraint requires that students only enter programs for which they are qualified. In particular, if $1-q_{i p g}=1$ then $d_{i g}^{p}=0$. The second constraint is the function governing how years of delay affect eligibility of a program. After one year of delay, students' GPAs are multiplied by 1.09 and after two years the multiplier is $1.18 .^{16}$ Specifically, if $G P A_{i}$ is a student's high school GPA and THGP $A_{p g+1}^{I I}$ is the minimum GPA required to enter under the Group II admissions class with a delay, then for $g \in\{0,1\}$,

$$
q_{i p g+1}=\left\{\begin{array}{l}
1 \text { if } G P A_{i} *\left(\mathbb{1}\left[G_{i g}=1\right] * 1.09+\mathbb{1}\left[G_{i g}=2\right] * 1.18\right) \geq \text { THGPA } A_{p g+1}^{I I} \\
0 \text { otherwise }
\end{array}\right.
$$

The third and fourth constraints specify the law of motion for the years of delay and require that students choose only one option in a period, respectively.

\footnotetext{
${ }^{16}$ In practice, the multipliers depended on how much work experience students have, however, because we do not observe hours, we assume that all students have the maximum GPA multiplier. Other proxies for full-time work meant that we observed many individuals entering programs for which they appeared unqualified.
} 
Further Parametrization and Specification of Expectations

We make further parametric assumptions that lead to a closed form solution to the optimization problem. In each period, we assume that the current-period preference shocks for schooling and delaying are known, but future shocks are still random. We also assume that, before committing to a choice, students can observe all the current-period threshold GPAs, and thus know $Q_{i g}$, which is the vector denoting the programs for which they are eligible. ${ }^{17}$ In contrast, when making their choices, students only know the expected present value of their student financial aid, their expected lifetime earnings in any given program, and their expected earnings during a year of delay. Under these assumptions,

$$
\begin{aligned}
\mathbb{E}_{g}\left[U_{i p g}^{S}\right] & =\alpha_{f}+\alpha_{x} X_{i p f}+\mathbb{E}_{g}\left[\text { PV } \text { earn }_{i p g}\right]+\mathbb{E}_{g}\left[P V S F A_{i g}\right]+\epsilon_{i p g}^{S} \\
\mathbb{E}_{g}\left[U_{i g}^{G}\right] & =\gamma_{s g}+\gamma_{h g}+\gamma_{c}+\gamma_{u} \text { unemp }_{i g}+\gamma_{a} \text { age }_{i g}+\mathbb{E}_{g}\left[\text { earn }_{i g}\right]+\epsilon_{i g}^{G}
\end{aligned}
$$

We estimate these expectations outside the model and provide a detailed description of how we do that in Online Appendix A.

To fully parameterize $V_{i g}\left(\epsilon_{i g}, Q_{i g}, G_{i g}\right)$, we also need to specify $\mathbb{E}\left[V_{i g+1}\left(\epsilon_{i g+1}, Q_{i g+1}, G_{i g+1}\right)\right]$. Starting from the $g=1$ point of view, the expected maximum utility in period 2, where $d_{i 2}^{0}=0$, is,

$$
\mathbb{E}_{1}\left[V_{i 2}\left(\epsilon_{i 2}, Q_{i 2}, 2\right)\right]=\mathbb{E}_{1}\left[\max _{d_{i g}} \sum_{p=1}^{30} d_{i 2}^{p} q_{i p 2} U_{i p 2}^{S}\right]
$$

When $g=1$, both $q_{i p 2}$ and $U_{i p 2}^{S}$ are stochastic. If we assume that $\epsilon_{i 2}$ is independent and identically drawn from an extreme value (type 1) distribution with a location equal to zero

\footnotetext{
${ }^{17}$ Although thresholds are unknown in June when students apply, we make this assumption because a) the application system was strategy proof, such that students had no incentive to misrepresent their true preferences in their rankings, b) before programs began, in September, the GPA cutoffs and the number of places still available were published. Thus, students who had not received an offer could choose one of the available programs before committing to delaying.
} 
and a scale of $\tau>0$, then, following McFadden (1977), we can write the expected value function, conditional on $Q_{i 2}$, as,

$$
\begin{aligned}
\mathbb{E}_{1}\left[V_{i 2}\left(\epsilon_{i 2}, Q_{i 2}, 2\right) \mid Q_{i 2}\right]= & \tau \ln \left[\sum_{p=1}^{30} q_{i p 2} \exp \left(\frac{1}{\tau} \bar{U}_{i p 2}^{S}\right)\right]+\lambda \tau \\
\text { Where : } & \bar{U}_{i p 2}^{S}=\alpha_{f}+\alpha_{x} X_{i p f}+\mathbb{E}_{2}[P V \text { earn } i p 2]+\mathbb{E}_{2}\left[P V S F A_{i 2}\right]
\end{aligned}
$$

In the last term of (11) $\lambda$ represents Euler's constant. ${ }^{18}$

To write down the unconditional expected value function, when $g=1$, we need to specify students' beliefs about the probability that $q_{i p 2}=1$ for all programs. A student is qualified for a program in period two if her GPA is above the Group II threshold in that period, which we will call $T H G P A_{p 2}^{I I}$. We assume that students believe that for each program $T H G P A_{p 2}^{I I}$ is independently and uniformly distributed with a support of $\left\{\underline{T H G P}_{p 2}^{I I}, \overline{T H G P A}_{p 2}^{I I}\right\}$. This means that if a student's own GPA is above $\overline{T H G P A}_{p 2}^{I I}$, then she believes that $P_{i p 2} \equiv \operatorname{prob}\left(q_{i p 2}=1\right)=1$. Conversely, if a student's own GPA is below $\underline{T H G P A}_{p 2}^{I I}$, then he believes that $P_{i p 2}=0$. This specification allows us to greatly reduce the dimensionality of the problem, which, if unconstrained, would involve integrating over $2^{30}$ choice sets. Given this parametrization, the unconditional expected value function, $\mathbb{E}_{1}\left[V_{i 2}\left(\epsilon_{i 2}, Q_{i 2}, 2\right)\right]$, is a weighted average of all the conditional expected value functions associated with each possible combination of programs for which a student might be qualified in period 2. The weights are the probabilities associated with being qualified for each combination of programs. ${ }^{19}$

\footnotetext{
${ }^{18}$ Euler's constant is defined as the limit of the difference between the natural log and a harmonic sequence and is equal to roughly 0.5772 . If a random variable follows an extreme value (type 1) distribution with a location equal to zero and a scale of $\tau$ then the mean of the random variable is $\tau \lambda$.

${ }^{19}$ An example of such a weighted average of conditional expected value functions is given in Online Appendix C.
} 
The structure of the expected value function in period 1 from the period 0 point of view has a similar structure except that $d_{i 1}^{0}=1$ is possible. Again, assuming that $\epsilon_{i 1}$ is i.i.d. extreme value with a location of zero and a scale of $\tau$, the conditional expected value function is:

$$
\begin{aligned}
& \mathbb{E}_{0}\left[V_{i 1}\left(\epsilon_{i 1}, Q_{i 1}, 1\right) \mid Q_{i 1}\right]= \\
& \tau \ln \left[\sum_{p=1}^{30} q_{i p 1} \exp \left(\frac{1}{\tau} \bar{U}_{i p 1}^{S}\right)+\exp \left(\frac{1}{\tau}\left(\bar{U}_{i 1}^{G}+\beta \mathbb{E}_{0}\left[V_{i 2}\left(\epsilon_{i 2}, Q_{i 2}, 2\right)\right]\right)\right)\right]+\lambda \tau
\end{aligned}
$$

We assume that all of the stochastic elements are independent across time periods, and that learning $Q_{i 1}$ in period 1 does not affect a student's forecast for $Q_{i 2}$. This implies that $\mathbb{E}_{0}\left[V_{i 2}\left(\epsilon_{i 2}, Q_{i 2}, 2\right)\right]=\mathbb{E}_{1}\left[V_{i 2}\left(\epsilon_{i 2}, Q_{i 2}, 2\right)\right]$.

The variable $Q_{i 1}$, which is random in period 0, depends on the Group II thresholds in period $1\left(T H G P A_{p 1}^{I I}\right)$. As in period 2, we assume that students believe that $T H G P A_{p 1}^{I I}$ is independently and uniformly distributed with a support of $\left\{\underline{T H G P A_{p 1}^{I I}}, \overline{T H G P A}_{p 1}^{I I}\right\}$. The only difference between the period 1 and period 2 threshold distributions is the GPA multiplier. After one year of delay, an individual's GPA is only multiplied by 1.09, whereas after two years the GPA is inflated by 1.18. Thus, for all thresholds above $6, \underline{T H G P A_{p 1}^{I I}=}$

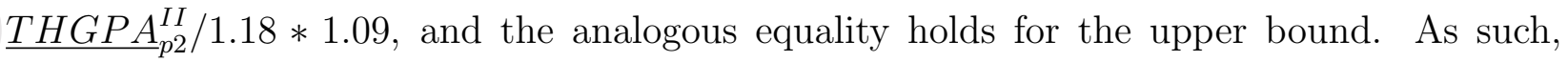
$\mathbb{E}_{0}\left[V_{i 1}\left(\epsilon_{i 1}, Q_{i 1}, 1\right)\right]$ will also be a weighted average of all possible $\mathbb{E}_{0}\left[V_{i 1}\left(\epsilon_{i 1}, Q_{i 1}, 1\right) \mid Q_{i 1}\right]$.

\section{Calibrating the Threshold Distributions}

We calibrate the upper and lower bounds on the GPA threshold distributions using data from the actual GPA cutoffs. In the archival reports published by central admissions authority, the minimum GPA thresholds are published for students who have the maximum Group II 
GPA multiplier, which is 1.18. We find the mean and standard deviation across the years 1979 to 1986 for each program. Then, we use one standard deviation above and below the mean to define the support of each program's threshold distribution after two years of delay. If one standard deviation below the mean is below the minimum GPA of 6 , then we use 6 as the truncation point. The support of the threshold distributions after one year of delay is found similarly, except we use 1.09 as the multiplier.

We truncate the distributions to limit the number of programs into which students are uncertain they will be admitted in the future. If we truncate at one standard deviation above and below the mean, the maximum number of programs over which any student is "uncertain" is ten, which requires computing a weighted sum of $2^{10}$ possible future choice sets. $^{20}$

\section{Estimation and Identification}

Because the solution to the model has a closed form, we use Maximum Likelihood to estimate the parameters of the model. In total, there are 21 parameters to estimate. The observed choices will identify, up to scale, the coefficients in the utility equations. The scale of the preference shocks, $\tau$, will fit differences in enrollment rates that are unexplained by the average choice-specific utilities, including differences in lifetime earnings. ${ }^{21}$

The variation in GPA thresholds, in both admissions groups, provides an important source of exogenous variation. Students' contributions to the likelihood function are conditional on the set of programs for which they are eligible, meaning their GPA is above the relevant

\footnotetext{
${ }^{20}$ In Online Appendix I, we report results from a model where we use the full support over the years 1979 to 1986. This appendix also includes models where the students believe the distributions are truncated normal and uniform with drift. Our key findings are robust to different assumptions about these beliefs.

${ }^{21}$ In Online Appendix D, we provide a more detailed discussion of the estimation method and the identifying variation.
} 
threshold. Because the GPA thresholds fluctuate based on aggregate demand and supply, individuals do not know exactly what future thresholds will be. The unpredictable fluctuations in the thresholds generates useful variation both within and across cohorts in the set of programs for which a student is eligible. Across cohorts, two students with the same GPA and the same set of characteristics, both observed and unobserved, will face a different set of program choices because of the year they graduate high school. Within a cohort, students with GPAs just above or below a threshold will face a different set of options, despite having similar grades. This variation also helps identify parameters in the value of delay because the set of options to which delaying is compared depends on the GPA thresholds. We show the threshold variation in Online Appendix D.

Although we do take advantage of the exogenous variation provided by the fluctuations in GPA thresholds, this does not guarantee that our independence assumption holds. A key concern stems from unobserved heterogeneity in expected future earnings. We discuss the implications of bias arising from this source in Online Appendix E.

\section{Results}

Once we have estimated the parameters, the structural model allows us to manipulate the GPA thresholds, and, using simulated data and shocks, investigate the distribution of choices under counterfactual admissions constraints. Because they are not of direct interest, we report the estimated parameters in Online Appendix F. In this section, we begin by evaluating the model by demonstrating how well it can predict the distribution of delay both in and out of sample. Following that discussion, we present the results from the counterfactual experiments. 
In assessing the fit of the model, our focus is on how well our model simulations can predict the distributions of delay. We use the sample period 1981-1984 to investigate how well the model performs in sample, and we use the 1980 cohort to examine the out-of-sample fit of the model. The simulated distributions were constructed by randomly drawing samples and a set of preference shocks 100 times and then determining the distribution of choices conditional on those shocks.

In Figure 1, we show, for each program, the fractions of students admitted without delay in the data and the simulations together with the Group I thresholds in each year. Overall, we believe the model simulations fit the data reasonably well. The simulations match the data best when the fraction of students admitted without delay in the data moves in the opposite direction of the GPA threshold. In these years, changes in the fractions of Group I enrollment quotas create changes in the excess demand for spots in the Group I admissions class, which drives changes in the GPA threshold. In the model, an increase in GPA thresholds leads to fewer programs in some students' choice sets, which would then tend to reduce the fraction entering without delay, and vice versa for decreases in thresholds. Fluctuations in the GPA thresholds provide the main source of identifying variation that drives the simulated decisions to delay university. Sex and high school track are also strong predictors of delaying and the field-of-study choice. As such, variation across cohorts in the share of women and students graduating from the math track also contribute to the fit of the model. In Online Appendix G, we report the extent to which we can match distributions within those subgroups. 

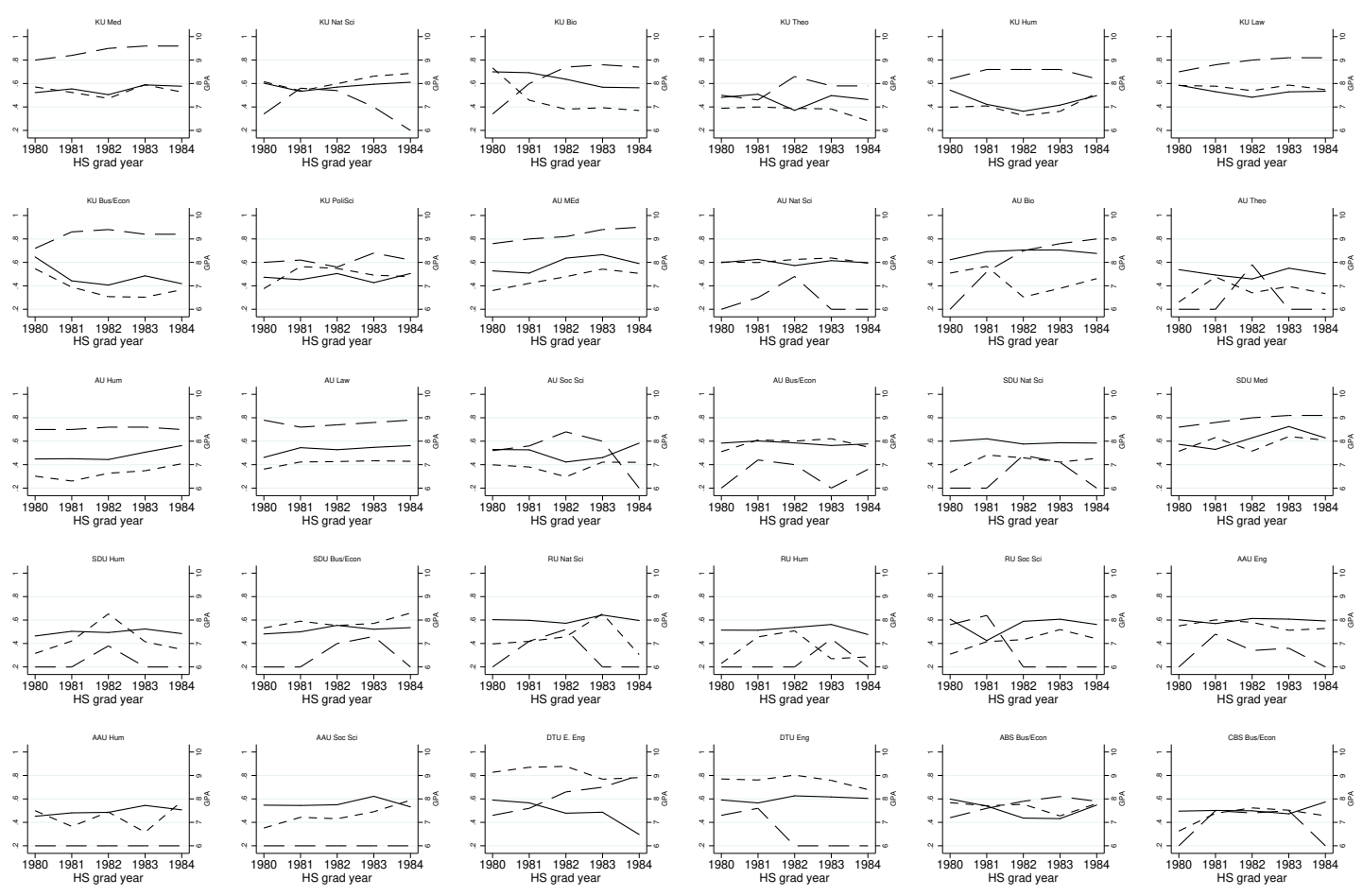

Simulation

- - - - Group I Threshold (Right Axis)

Figure 1: Fraction of Entering Each Program Without Delay, Simulated and Data: 1980-1984

University abbreviations in the panel titles are KU, University of Copenhagen; AU, Aarhus University; SDU, University of Southern Denmark; RU, Roskilde University; AAU, Aalbourg University; DTU, Danish Technical University; ABS, Aarhus Busines School. Field-of-study abbreviations are Med, Medical programs; Nat Sci, Natural Sciences; Bio, Biology; Theo, Theology; Hum, Humanities; Bus/Econ, Business and Economics; PoliSci, Political Science; Soc Sci, Social Sciences; Eng, Engineering; E. Eng, Electrical Engineering.

\section{Delaying under Counterfactual Admissions Constraints}

The main purpose of our counterfactual experiments is to analyze the extent to which individuals alter the timing of entry into university because they are constrained from entering

their preferred program. The counterfactuals are not meant to represent policies that could be cost-effective to implement, but instead allow us to use revealed preference arguments to infer students' optimal behaviour, and from that the constraints they face. We do use the experiments to investigate whether students respond to incentives to change their delaying behaviour, and, in that sense, they can inform the potential effectiveness for such policies. 
However, since the thought experiments represent extreme interventions, which would entail enormous costs to implement, our findings are indicative of the maximum scope for impact.

The counterfactuals reveal how the existing stock of enrolled university students would respond to changes in the admissions constraints, holding constant the direct utility of delaying and the utility of entering a program following any given years of delay. In each of the experiments, we allow the number of positions available in all programs to expand to meet demand among students qualified under the particular set of GPA thresholds. We also hold expected life-time earnings constant for each choice pathway. Essentially, we do not allow for any general equilibrium effects stemming from, for example, changes in the relative number of doctors. Since, in our model, we condition on enrolling in university within two years of high school graduation, our counterfactual experiments do not allow for new enrollments. Because of this, each experiment weakly expands the set of choices available to each student. This is important because, if we restricted the choice set, some students might prefer 'no university' to the constrained set of choices.

To implement the counterfactual experiments, we maintain all other structural elements of the model and alter the GPA thresholds faced by students. We randomly draw a sample of students and their preference shocks 100 times, and using the estimated parameters, we solve the model for each student's optimal choice. Finally, we summarize the resulting distributions of years of delay and fields of study.

In Table 4, we show the distributions of delay that are generated by each of three different experiments, along with the 'baseline' case, which refers to the simulated results using the actual GPA thresholds from 1981-1984. The first experiment, called 'free entry', eliminates the GPA thresholds from all programs in all years. This is essentially completely open 
Table 4: Counterfactual Admissions Constraints: Distribution of Delay (Standard Errors in Parentheses)

\begin{tabular}{|c|c|c|c|c|}
\hline & Baseline & $\begin{array}{l}\text { Free } \\
\text { Entry }\end{array}$ & $\begin{array}{c}\text { Free Entry } \\
\text { with no delay }\end{array}$ & $\begin{array}{c}\text { Free Entry } \\
\text { Except Med. }\end{array}$ \\
\hline 0 years delay & $\begin{array}{c}0.5468 \\
(0.0041)\end{array}$ & $\begin{array}{c}0.6400 \\
(0.0042)\end{array}$ & $\begin{array}{c}0.6572 \\
(0.0042)\end{array}$ & $\begin{array}{c}0.6456 \\
(0.0039)\end{array}$ \\
\hline 1 year delay & $\begin{array}{c}0.2937 \\
(0.0031)\end{array}$ & $\begin{array}{c}0.2546 \\
(0.0029)\end{array}$ & $\begin{array}{c}0.2239 \\
(0.0028)\end{array}$ & $\begin{array}{c}0.2425 \\
(0.0030)\end{array}$ \\
\hline 2 years delay & $\begin{array}{c}0.1595 \\
(0.0034)\end{array}$ & $\begin{array}{c}0.1054 \\
(0.0026)\end{array}$ & $\begin{array}{c}0.1190 \\
(0.0028)\end{array}$ & $\begin{array}{c}0.1119 \\
(0.0025)\end{array}$ \\
\hline
\end{tabular}

Notes: Distributions of delay are simulated under different counterfactual admissions constraints. The baseline specification uses the model admissions constraints. "Free Entry" means there are no restrictions on any program in any period. Under the "Free Entry with no Delay" counterfactual there are no restrictions if students enter university directly from university, but if they delay they face the usual model restrictions after one or two years of delay. "Free Entry Except Med" means there are no restrictions in any period in every other program except Medical programs, for which the model restrictions apply in every year.

admissions for high school graduates with a GPA of at least 6. In the free-entry experiment, students reveal their wholly unconstrained choices in terms of both the timing of entry and the field of study entered.

Compared to the baseline, the percentage of students who enter university directly from high school increases from $54.68 \%$ to $64.00 \%$. Of this 9.32 percentage point increase, roughly $60 \%$ is generated by a reduction in delaying by two years. This shift in the distribution of delay are the net effect of two different and counteracting incentives that are generated by eliminating both the admissions constraints and the risk associated with future GPA thresholds.

In the baseline policy environment, there is, potentially, a set of students who delay because their GPA is below the threshold of their preferred program in a given year. The elimination of thresholds in the free-entry experiment, holding all else constant, should induce these students to reduce their years of delay. There is a less obvious and countervailing effect that could occur because there is no risk associated with future GPA thresholds in the freeentry experiment. There might be some students in the baseline environment who would 
prefer to delay to a future period, but enter university in the current period because of the presence of future risk. The elimination of risk, in the open admissions environment, would tend to encourage these students to delay more often or for more years. ${ }^{22}$

To disentangle these two effects and to quantify their magnitudes, we calculate the gross flows from the years of delay in the baseline to that in the free-entry environment. These flows are reported in Table 5, where the rows and columns correspond to the baseline and free-entry environments, respectively. The number in each cell represents a fraction of the entire simulated sample; as such, the sum of all cells in the table is one.

The sum along the diagonal of Table 5 , which is $86.33 \%$, represents the fraction of students who, relative to the baseline, do not alter their years of delay in the free-entry experiment. A revealed-preference argument suggests that these students are unconstrained, in terms of the timing of entry, in the baseline admissions environment. When all options are available, the students choose the same years of delay as they do in the baseline, implying that the relevant baseline constraints do not bind for this group of students.

Table 5: Gross flows in the distribution of delay from the baseline to the free entry experiment

Free Entry

\begin{tabular}{ccc} 
Zero years & One year & Two years \\
& & \\
0.5370 & 0.0071 & 0.0028 \\
0.0652 & 0.2261 & 0.0024 \\
0.0378 & 0.0215 & 0.1002 \\
\hline
\end{tabular}

Notes: The joint distribution of delay in the baseline and "Free Entry" counterfactuals is reported. The baseline specification uses the model admissions constraints. "Free Entry" means there are no restrictions on any program in any period.

The fraction of the simulated sample who decrease their years of delay in the free-entry experiment is found by summing the lower off-diagonal cells in Table 5. These cells sum to

\footnotetext{
${ }^{22}$ Eliminating the admissions risk, while holding constant the GPA thresholds, creates a different set of incentives that we discuss in Supplement Appendix K.
} 
$12.45 \%$ of the simulated sample, representing $27.47 \%$ of all baseline delayers. From revealedpreferences, and because we hold constant all other modelled facets of utility, we can infer that these students delay because they could not enter a preferred program in an earlier period. Among the students who enter more quickly in the unconstrained and risk-free experiment, most enter university directly from high school. Specifically, $10.30 \%$ of the simulated sample are baseline delayers who enter university after zero years of delay in the free-entry experiment, and $2.15 \%$ reduce their delay from two years to one.

The sum of the upper off-diagonal cells reports the opposite effect of the free-entry experiment, relative to baseline. That sum reveals that $1.23 \%$ of the simulated sample increase their years of delay. This effect is driven by the elimination of future risk in the free-entry experiment. For these students, in the absence of risk and when their choices are unconstrained, delaying and entering a program in a future period dominates entering any program in the current period.

When comparing the baseline to unconstrained admissions, the 9.32 percentage point net increase in direct entry results from the $10.30 \%$ gross increase in the fraction with zero years of delay minus the $.99 \%$ who flow from zero years of delay to at least one year of delay. Thus, in the 1981-1984 sample period, the dominant effect of the admissions system on the timing of university enrollment is to increase years of delay. Overall, however, for the vast majority, more than $85 \%$, the admissions constraints have no effect on when students enter university.

The next experiment, reported in the third column of Table 4, combines free entry after zero years of delay with the baseline environment after at least one year of delay. This counterfactual is labeled "free entry with no delay", and we will call it the "no-delay" experiment for ease of exposition. In this experiment, students can enter any program if they enter 
directly from high school; if they delay then they face the usual Group II GPA thresholds, and the risk associated with fluctuations in those thresholds. This experiment focuses the admissions incentives on entering with zero years of delay, and, as a side effect, shuts down the free-entry incentive to delay by one year among those who enter directly in the baseline.

Comparing the fraction of the simulated sample who enter university directly from high school in the baseline to that in the no-delay experiment reveals a net increase of 11.04 percentage points. Within the sample period, this is the largest effect on delaying that policies which relax admissions constraints might induce. Again, it is worth emphasizing that fully opening admissions is an extreme case. A policy that is feasible to implement would likely have more modest effects.

Using the free-entry experiment as a benchmark with which to compare the no-delay experiment contrasts an unconstrained and risk-free distribution of choices to one in which direct entry is incentivized. When the Group II admissions class was created policy makers thought students would benefit from work experience prior to entering university. We do not evaluate the impact of delaying, but there is evidence using similar data from Sweden to suggest that delaying reduces lifetime earnings (Holmlund et al., 2008). For this reason, particularly if tax revenues are also reduced, governments might want to encourage students to enter directly, even if that is not their unconstrained choice.

In Table 6, we report the gross flows from years of delay in the free-entry experiment to the no-delay experiment. Again, the cells sum to one. Since, in both experiments, students are free to enter any program they choose after zero years of delay, and because all other aspects of utility are held constant, all of the students who enter directly in the free-entry experiment do the same in the no-delay experiment. This group represents $64 \%$ of the simulated sample. 
Table 6: Gross flows in the distribution of delay from free entry to the free entry without delay experiment

\begin{tabular}{lccc}
\hline & & Free Entry Without Delay \\
& & One year & Two years \\
\cline { 2 - 3 } & Zero years & & \\
Free Entry & & & 0.0000 \\
Zero years & 0.6400 & 0.2216 & 0.0000 \\
One year & 0.0124 & 0.0023 & 0.0983 \\
Two years & 0.0047 & \\
\hline \hline
\end{tabular}

Notes: The joint distribution of delay in the "Free Entry" and "Free Entry Without Delay" counterfactuals is reported. "Free Entry" means there are no restrictions on any program in any period. Under the "Free Entry with no Delay" counterfactual there are no restrictions if students enter university directly from university, but if they delay they face the usual model restrictions after one or two years of delay.

The percentage of the simulated sample that was induced, from their free-entry choice, by the no-delay experiment to reduce their years of delay to zero is only $1.72 \%$. That this effect is so small suggests that among those who, in the baseline environment, delay because their GPA is below the threshold of a preferred program, most would, in the absence admissions restrictions, prefer to enter directly.

Because both the free-entry and no-delay experiments allow students to enter any program, the changes in the distribution of delay may result from substantial shifts in the distribution of field of study. In Table 7, we report the resulting distributions of field of study for the baseline, the free-entry experiment, and a third counterfactual, which we will discuss shortly. Relative to the baseline, in the free-entry experiment, the net flow is primarily into medicine, which is among the programs with the highest excess demand. Although the shares in all other fields contract, the largest reduction is in Engineering.

To further investigate this net difference in the field of study, and how it is related to the changes in delay, we calculate the gross flows across the joint distribution of delay and fields. There are 15 outcomes in the joint distribution, and in Table 8 we report the fraction of the simulated sample flowing from each of the outcomes in baseline to each outcome in 
Table 7: Counterfactual Admissions Constraints: Distribution of Field of Study (Standard Errors in Parentheses)

\begin{tabular}{|c|c|c|c|}
\hline & Baseline & $\begin{array}{l}\text { Free } \\
\text { Entry }\end{array}$ & $\begin{array}{c}\text { Free Entry } \\
\text { Except Med. }\end{array}$ \\
\hline Humantities & $\begin{array}{c}0.1475 \\
(0.0023)\end{array}$ & $\begin{array}{c}0.1200 \\
(0.0020)\end{array}$ & $\begin{array}{c}0.1391 \\
(0.0022)\end{array}$ \\
\hline Natural Science & $\begin{array}{c}0.1858 \\
(0.0030)\end{array}$ & $\begin{array}{c}0.1503 \\
(0.0029)\end{array}$ & $\begin{array}{c}0.1832 \\
(0.0032)\end{array}$ \\
\hline Social Science & $\begin{array}{c}0.3663 \\
(0.0041)\end{array}$ & $\begin{array}{c}0.3530 \\
(0.0045)\end{array}$ & $\begin{array}{c}0.4066 \\
(0.0048)\end{array}$ \\
\hline Engineering & $\begin{array}{c}0.2298 \\
(0.0031)\end{array}$ & $\begin{array}{c}0.1685 \\
(0.0027)\end{array}$ & $\begin{array}{c}0.2014 \\
(0.0030)\end{array}$ \\
\hline Medical programs & $\begin{array}{c}0.0706 \\
(0.0015)\end{array}$ & $\begin{array}{c}0.2083 \\
(0.0046)\end{array}$ & $\begin{array}{c}0.0696 \\
(0.0015)\end{array}$ \\
\hline
\end{tabular}

Notes: Distributions of field of study are simulated under different counterfactual admissions constraints. The baseline specification uses the model admissions constraints. "Free Entry" means there are no restrictions on any program in any period. "Free Entry Except Med." means there are no restrictions in any period in every other program except Medical programs, for which the model restrictions apply in every year.

the free-entry experiment.

The diagonal in this table, which is shaded dark grey, represents the sample who did not change their field of study or their years of delay in the free-entry experiment. The sum of those cells totals $73.06 \%$. Among those who did change their choice, there are three different types of movement. First, students might alter their timing of entry but remain in the same field of study. These outcomes are shaded light grey. Less than one percent of the sample increase their years of delay and $2.76 \%$ enter after fewer years of delay, while remaining in their baseline field. This latter group of students are primarily those who enter the high excess-demand fields of Medicine and Social Science.

The second type of movement involves changing the field of study without altering the timing of entry. More than $13 \%$ of the sample make such a change. From the point of view of a policy maker hoping to encourage direct entry this would be the least desirable behavioural response. Indeed, most of this movement, $8.23 \%$ of the sample, is generated by flows into Medicine. 


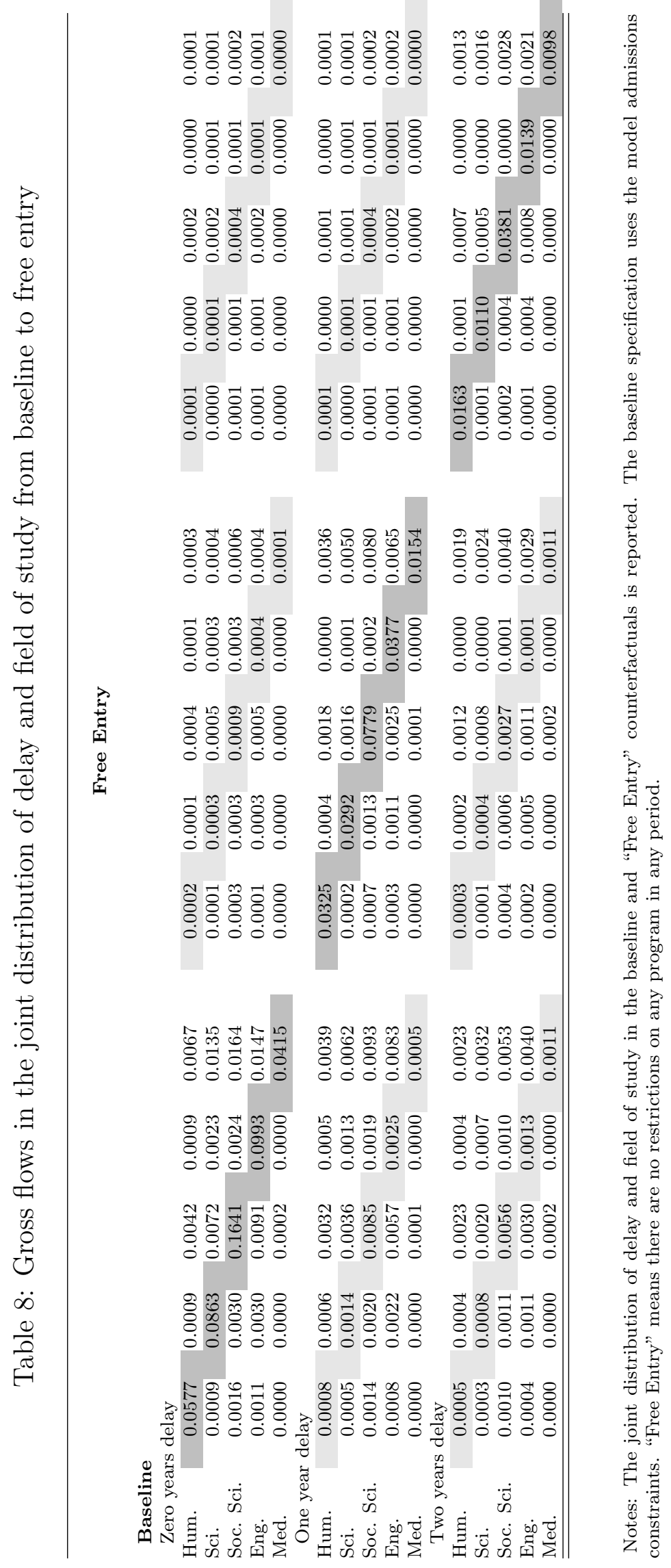


Finally, the third type of movement, made by $10.56 \%$ of the sample, involves shifts in both field and years of delay. Two fifths of this group are students who delay in the baseline and then enter Medicine without delay in the free-entry experiment. Although students from all other baseline fields flow into Medicine, the largest shares come from the baseline fields of Engineering and Social Sciences.

As we noted previously, $12.45 \%$ of the simulated sample reduce their years in the freeentry experiment relative to baseline. Of those students, $43.01 \%$, which is roughly $5 \%$ of the whole sample, switch from their baseline field into Medicine. Because such a large fraction of the reduction in delay is driven by the flow into Medicine, we perform a third experiment that removes the admissions constraints in all years from all programs except Medicine. We call this experiment "free entry, except Medicine."

The distribution of delay in this counterfactual is reported in the fourth column of Table 4 and the distribution of fields is reported in the third column of Table 7. When students can freely enter any program except Medicine, we observe a distribution of delay that is very similar to that in the free-entry experiment. Similarly, the free-entry-except-Medicine experiment increases direct entry by 9.9 percentage points relative to baseline. In contrast, however, the distribution of fields in the free-entry-except-Medicine experiment is relatively close to the baseline distribution. The share in Social Sciences increases by 4.03 percentages points, drawing mostly from Engineering. The free-entry-except-Medicine essentially shuts down much of the "windfall" behaviour in which students enter Medicine without reducing delay. ${ }^{23}$ Although, in general, our findings imply that relaxing admissions restrictions will

\footnotetext{
${ }^{23}$ The gross flows across the joint distribution of delay and fields from the baseline to the free free-entryexcept-Medicine experiment are reported in Online Appendix H.
} 
not dramatically reduce delay, this particular finding does suggest in designing such policies, it is important to consider the impact on high excess-demand programs.

\section{Conclusion}

We investigate the extent to which the common practice of delaying university among Danish students is affected by admissions restrictions. This question is motivated by the observation that the propensity to delay varies substantially across field of study. We study the admissions policies active in the early 1980's. The policies from this period share many key features with current policies in Denmark and other Nordic countries, and are more generally applicable whenever excess demand creates admissions constraints in competitive programs. In the Danish context, admissions constraints arise because of fixed enrollment quotas.

We model the Danish policy environment using a dynamic discrete choice model in which high school graduates choose whether to enter a program into which they have been admitted in that period or to delay to the next period. The set of program choices in future periods fluctuate unpredictably, and this generates an incentive for some to delay and conversely for others to enter directly. In the context of the random GPA thresholds, our use of structure has two advantages. First, we exploit the exogenous changes, within and between cohorts, in minimum GPA thresholds to help identify the model. Second, the structure allows us to quantify the gross effects of the two countervailing incentives.

We find that the incentive to delay dominates the incentive to enter directly. However, our simulations also suggest that the percentage of high school graduates delaying university would only fall by 9.32 percentage points in a completely open admissions system. This is primarily because, among the students who delay, less than one third do so because of 
admissions restrictions. For a host of reasons, including the direct costs it would entail, fully opening admissions is not a reasonable policy. Instead, we think of this as a thought experiment that is informative of the maximum possible impact of easing admissions constraints.

In the Danish type of admissions system, the minimum GPA restrictions in some programs always bind for some students because the restriction only exists when there is excess demand. As such, our results imply that although students are constrained by the fixed supply of positions, not all of those students are willing to delay because of the constraints. Across systems, one would expect the fraction of students affected by restrictions to vary with the fraction of all university positions with minimum GPA requirements. It is also worth emphasising, we do not model the decision to enter university, in part, because there is always at least one program into which any high school graduate would be admitted in our sample period. In highly competitive systems, admissions restrictions may affect that margin.

Overall, for policy makers interested in accelerating young people's entry into the fulltime labour market, in systems with comparable levels of excess demand, our results suggest that there is limited scope to substantially reduce the amount of delaying with programs that give students who apply directly from high school advantages in admissions. Although we do not study this issue directly, financial incentives, which have been shown to reduce the time taken to complete a degree (Garibaldi et al., 2012; Gunnes et al., 2013), may prove more effective. 


\section{References}

Altonji, J.G., P. Arcidiacono, and A. Maurel, The Analysis of Field Choice in College and Graduate School, Vol. 5 of Handbook of the Economics of Education, Elsevier, June

Altonji, Joseph G., Erica Blom, and Costas Meghir, "Heterogeneity in Human Capital Investments: High School Curriculum, College Major, and Careers," Annual Review of Economics, 07 2012, 4 (1), 185-223.

Arcidiacono, Peter, "Ability sorting and the returns to college major," Journal of Econometrics, 2004, 121 (1-2), 343-375.

_, V. Joseph Hotz, Arnaud Maurel, and Teresa Romano, "Recovering Ex Ante Returns and Preferences for Occupations using Subjective Expectations Data," NBER Working Papers 20626, National Bureau of Economic Research, Inc October 2014.

Crawford, Claire and Jonathan Cribb, "Gap year takers: uptake, trends and long term outcomes," Technical Report, Institute for Fiscal Studies through the Centre for Analysis of Youth Transitions (CAYT) 2012.

Daly, Moira and Daniel le Maire, "University admission and preferred field of study," Working Paper, 2019.

Eurostudent, Social and Economic Conditions of Student Life in Europe. Eurostudent VI 2016-2018 - Synopsis of Indicators, Bielefeld: W. Bertelsmann Verlag, 2015.

Ferrer, Ana M. and Alicia Menendez, "The Puzzling Effects of Delaying Schooling on Canadian Wages," Canadian Public Policy, September 2014, 40 (3), 197-208.

Garibaldi, Pietro, Francesco Giavazzi, Andrea Ichino, and Enrico Rettore, "College Cost and Time to Complete a Degree: Evidence from Tuition Discontinuities," The Review of Economics and Statistics, August 2012, 94 (3), 699-711.

Gunnes, Trude, Lars J. Kirkebøen, and Marte Rønning, "Financial incentives and study duration in higher education," Labour Economics, 2013, 25 (C), 1-11.

Hastings, Justine S., Christopher A. Neilson, and Seth D. Zimmerman, "Are Some Degrees Worth More than Others? Evidence from college admission cutoffs in Chile," NBER Working Papers 19241, National Bureau of Economic Research, Inc July 2013.

Heinesen, Eskil, "Admission to higher education programmes and student educational outcomes and earnings-Evidence from Denmark," Economics of Education Review, 2018, $63(\mathrm{C}), 1-19$.

Holmlund, Bertil, Qian Liu, and Oskar Nordström Skans, "Mind the gap? Estimating the effects of postponing higher education," Oxford Economic Papers, October 2008, 60 (4), 683-710.

This article is protected by copyright. All rights reserved. 
Humlum, Maria Knoth, Jannie H.G. Kristoffersen, and Rune Vejlin, "College admissions decisions, educational outcomes, and family formation," Labour Economics, $2017,48(\mathrm{C}), 215-230$.

Kirkeboen, Lars J., Edwin Leuven, and Magne Mogstad, "Field of Study, Earnings, and Self-Selection," The Quarterly Journal of Economics, 2016, 131 (3), 1057-1111.

Lemieux, Thomas, "Occupations, fields of study and returns to education," Canadian Journal of Economics, November 2014, 47 (4), 1047-1077.

Light, Audrey, "The Effects of Interrupted Schooling on Wages," The Journal of Human Resources, 1995, 30 (3), pp. 472-502.

McFadden, Daniel L., "Modelling the Choice of Residential Location," Cowles Foundation Discussion Papers 477, Cowles Foundation for Research in Economics, Yale University 1977.

Monks, James, "The impact of college timing on earnings," Economics of Education Review, October 1997, 16 (4), 419-423.

Nielsen, Helena Skyt, Torben Sørensen, and Christopher Taber, "Estimating the Effect of Student Aid on College Enrollment: Evidence from a Government Grant Policy Reform," American Economic Journal: Economic Policy, May 2010, 2 (2), 185-215.

Peter, Kathryn Rooney Horn Laura Katharin and Andrew G. Malizio, "Profile of Undergraduates in U.S. Postsecondary Institutions: 1999 - 2000," Technical Report, National Center for Education Statistics 2002.

Sorensen, Henning, "Conscription in Scandinavia During the Last Quarter Century: Developments and Arguments," Armed Forces \&3 Society, Winter 2000, 26 (2), 313-334.

This article is protected by copyright. All rights reserved. 